\title{
Bilateral Adductor Nerve Palsy Following Total Thyroidectomy: A Case
} Report

\author{
Prashant Bhatt, ${ }^{1}$ Apar Pokharel ${ }^{1}$ \\ 'Department of Otorhinolaryngology and Head and Neck Surgery, College of Medical Sciences, Bharatpur, Chitwan, \\ Nepal.
}

\section{ABSTRACT}

Recurrent Laryngeal Nerve palsy following thyroidectomy is usually attributed to the surgery whereas sometimes the cause can be non-surgical and can result in adductor palsy. Bilateral Recurrent Laryngeal Nerve paralysis is rare complication of thyroidectomy. We present a case of a 35 year old female who developed dysphonia following thyroidectomy. The clinical findings and recovery were suggestive of a non-surgical cause for the palsy. The management of these patients differs and the knowledge in this regard is very important for the surgeons. The non-surgical and surgical cause of adductor palsy differs in presentation and management. Tracheostomy is not required and recovery of the nerve occurs in most cases.

Keywords: palsy; recurrent laryngeal nerve; total thyroidectomy.

\section{INTRODUCTION}

Bilateral Recurrent Laryngeal Nerve (RLN) paralysis is an uncommon complication of thyroidectomy (seen in $0.4 \%$ ), the commonest surgery that puts normally functioning laryngeal nerves at risk of injury. ${ }^{1,2}$ Injury to the RLN could be temporary or permanent, unilateral or bilateral. Recent study showed that the likelihood of temporary RLN paralysis is higher in bilateral near total thyroidectomy compared to bilateral total thyroidectomy. ${ }^{3}$ Bilateral RLN paralysis is a major risk factor for dysphonia, airway obstruction and is significantly associated with post- thyroidectomy vocal cord paralysis and long term risks of hospital readmission, dysphagia, hospitalization for lower respiratory tract infection and tracheostomy/gastrostomy.

\section{CASE REPORT}

We present a case of 35-year-old female who came to the out-patient department with a complaint of swelling in the anterior aspect of neck for 6 months. A thorough workup was done.
USG revealed a swelling of $15 \times 5 \times 3 \mathrm{~mm}$ in the right lobe of thyroid and a swelling of $1.5 \times 1.5 \times 1 \mathrm{~mm}$ in the left lobe of thyroid. FNAC revealed it to be papillary carcinoma thyroid. Thyroid function test and serum calcium levels were within normal range. Intraoperative course was uneventful.

On first post-operative day the patient developed aphonia and on second post-operative day she developed an attack of tetany. Hypocalcemia was managed aggressively with calcium gluconate, oral calcium and vitamin $D_{3}$. Serum calcium and magnesium levels were monitored and supplemented accordingly. Nasopharyngolaryngoscopy (NPL) was done which showed that the patient had developed a bilateral adductor palsy of the vocal cords (Figure 1).

Correspondence: Dr. Prashant Bhatt, Department of Otorhinolaryngology and Head and Neck Surgery, College of Medical Sciences, Bharatpur, Chitwan, Nepal. Email: bhattprashant1024@gmail. com, Phone: $+977-9851144922$. 


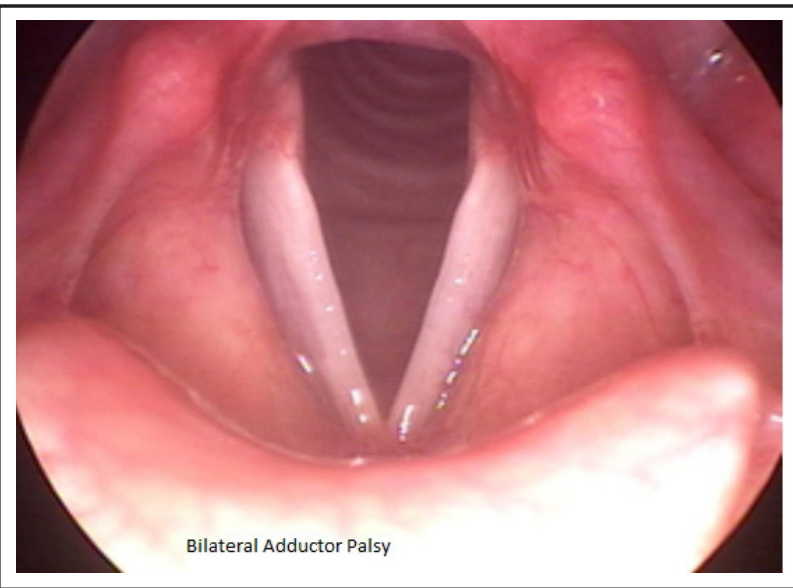

Figure 1. NPL showing bilateral adductor vocal cord palsy.

Patient was discharged after the calcium level was normal and there were no features of hypocalcemia. NPL was done at discharge for aphonia again and same results as before were obtained. Patient was called for a follow up after speech therapy. Patient also received radioiodine therapy.

Some improvement in voice was noticed and NPL revealed mild flickering movement of the vocal cords at follow up in 4 weeks. There were no features of hypocalcemia at this time.

There was a significant improvement in voice and NPL revealed vocal cords to be mobile at 12 weeks time (Figure 2).

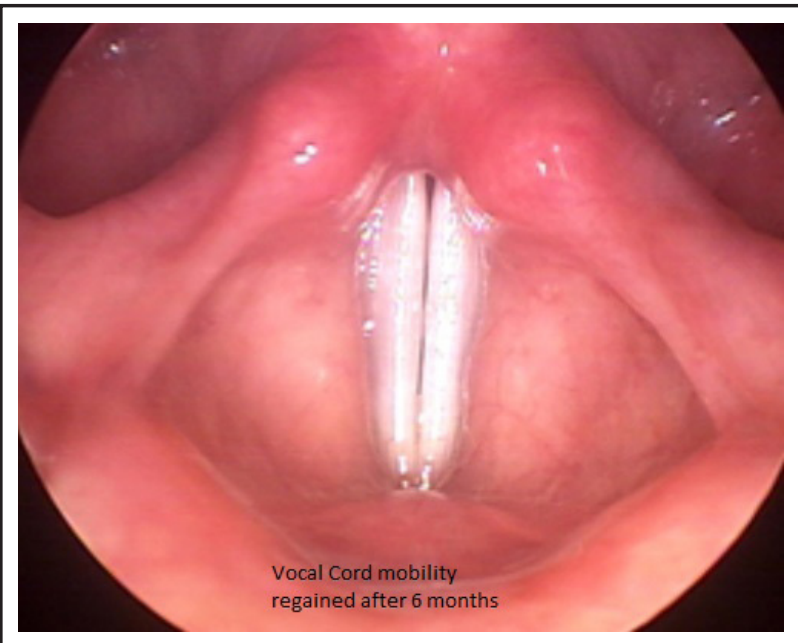

Figure 2. NPL showing spontaneous adduction of both vocal cords 3 months after surgery.

\section{DISCUSSION}

The anterior branch of the RLN supplies the adductor muscles of the vocal cord, injury of which leads to the abduction of the vocal cords which leads to hoarseness of voice and aspiration but shouldn't compromise the airway. As the airway is patent tracheostomy is not required in these patients. Knowledge in this regard decreases morbidity associated. Recovery of the function occurs usually, provided there is no permanent damage due to ischemia.

Vocal cord dysfunction due to injury of the laryngeal nerve is an important complication to have knowledge about in case of thyroid surgery, the consequences can be extremely dangerous. Efforts should be taken by surgeons to limit such occurrences through a thorough understanding of the surgical anatomy, the use of loupes magnification and intra-operative nerve monitoring. The reported incidence of bilateral vocal cord palsy remains very low, ranging from 0.58 to $0.63 \% .4,5$ The British Association of Endocrine and Thyroid Surgeons (BAETS) recommend that surgeons should be performing a minimum of 20 thyroidectomies per year to be considered safe ${ }^{6}$ and Adam et al. (2017) concluded that surgeons performing more than 25 per year had better patient outcomes. ${ }^{7}$ In the literature to date, there have been no reports of bilateral vocal cord palsy following hemithyroidectomy.

Non-surgical causes of vocal cord dysfunction are well known and include hypocalcaemia, low vitamin D levels ${ }^{8}$ and as a side effect of Cisplatin and vinca alkaloid based chemotherapy agents. ${ }^{9}$ Hypocalcaemia which is seen more frequently following total thyroidectomy is a well-known complication. ${ }^{10}$ In the present case study, the post-operative blood work up including corrected calcium, vitamin $D$ and magnesium were with in normal range.

Numerous case reports in the literature show RLN dysfunction following endotracheal intubation due to compression. ${ }^{11,12}$ Cavo (1985) found 6 cases of postoperative bilateral vocal cord palsy in the literature (prior to 1985), none of which were following thyroid surgery. ${ }^{13}$ Using cadaveric models to investigate the mechanism of injury, he concluded that compression of the anterior branch of the nerve occurred against the rigid thyroid lamina, 6-10 $\mathrm{mm}$ below the posterior end of the free edge of the vocal cord. He also investigated the fluctuation in cuff pressure depending on the gas used to inflate the cuff, and found that pressure in cuffs inflated with air as in our routine practice increased by 8-10 $\mathrm{mmHg}$ due to diffusion of nitrous oxide across the cuff membrane. Although not routine practice, if inflated with anaesthetic gases, he found little fluctuation in cuff pressure throughout the procedure. He also suggested various measures to prevent problems associated with the increased endotracheal cuff pressure. Nuutinen et al. (1981) and Vyshnavi et al. (2013) concluded that 
overextension of the neck during intubation resulted in stretching of the vagus nerves. In our case, the patient was positioned with her neck extended, with a shoulder roller and head ring in position. ${ }^{13,14}$
Consent: JNMA Case Report Consent Form was signed by the patient and the original is attached with the patient's chart.

\section{Conflict of Interest: None.}

\section{REFERENCES}

1. Cannizzaro MA, Bianco SL, Picardo MC, Provenzano D, Buffone A. How to avoid and to manage post-operative complications in thyroid surgery. Updates Surg. 2017 Jun 1;69(2):211-5. [PubMed | Full Text | DOI]

2. Nouraei SA, Allen J, Kaddour H, Middleton SE, Aylin $\mathrm{P}$, Darzi A, et al. Vocal palsy increases the risk of lower respiratory tract infection in low-risk, low-morbidity patients undergoing thyroidectomy for benign disease: A big data analysis. Clin Otolaryngol. 2017 Dec;42(6):1259-66. [Full Text | DOI]

3. Dinc T, Kayilioglu SI, Simsek B, Guldogan CE, Gulseren MO, Saylam B, et al. The evaluation of the complications observed in patients with bilateral total and bilateral near total thyroidectomy. Ann Ital Chir. 2017;88:198-201. [PubMed]

4. Ayala MA, Yencha MW. Outpatient thyroid surgery in a low-surgical volume hospital. World J Surg. 2015 Sep;39(9):2253-8. [ull Text | DOI]

5. Zakaria HM, Al Awad NA, Al Kreedes AS, Al-Mulhim AM, Al-Sharway MA, Hadi MA, et al. Recurrent laryngeal nerve injury in thyroid surgery. Oman Med J. 2011 Jan;26(1):34. [PubMed | Full Text | DOI]

6. British Association of Endocrine Surgeons. Guidelines for the Surgical Management of Endocrine Disease and Training Requirements for Endocrine Surgery [Internet]. London (UK): Royal College of Surgeons; 1999 [revised 2006; cited 2019]. Available from: https://www.baets.org.uk/ wp-content/uploads/2013/02/BAETS-Guidelines-2003 pdf. [Full Text]

7. Adam MA, Thomas S, Youngwirth L, Hyslop T, Reed $\mathrm{SD}$, Scheri RP, et al. Is there a minimum number of thyroidectomies a surgeon should perform to optimize patient outcomes? Ann Surg. 2017 Feb 1;265(2):402-7. [Full Text | DOI]

8. Büyükcam F, Sönmez FT, Şahinli H. A delayed diagnosis: stridor secondary to hypocalcemia. Int J Emerg Med. 2010 Oct 23;3(4):461-2. [․ㅏll Text | DOI]

9. Myssiorek D. Recurrent laryngeal nerve paralysis: anatomy and etiology. Otolaryngol Clin North Am. 2004 Feb;37(1):25-44. [Full Text | DOI]

10. Bourrel C, Uzzan B, Tison P, Despreaux G, Frachet B, Modigliani E, et al. Transient hypocalcemia after thyroidectomy. Ann Otol Rhinol Laryngol. 1993 Jul;102(7):496-501. [PubMed | Full Text | DOI]

11. Cavo JW Jr. True vocal cord paralysis following intubation. Laryngoscope. 1985 Nov;95(11):1352-9. [․ㅏll Text | DOI]

12. Jeong DM, Kim GH, Kim JA, Lee SM. Transient bilateral vocal cord paralysis after endotracheal intubation with double-lumen tube-A case report. Korean J Anesthesiol. 2010

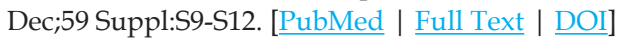

13. Nuutinen J, Kärjä J. Bilateral vocal cord paralysis following general anesthesia. Laryngoscope. 1981 Jan;91(1):83-6.

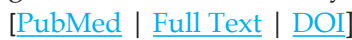

14. Vyshnavi S, Kotekar N. Aphonia following tracheal intubation: An unanticipated post-operative complication. Indian J Anaesth. 2013 May;57(3):306-8. [uㅏMed | Full Text | DOI]

The Author(s) 2018

This work is licensed under a Creative Commons Attribution 4.0 International License. The images or other third party material in this article are included in the article's Creative Commons license, unless indicated otherwise in the credit line; if the material is not included under the Creative Commons license, users will need to obtain permission from the license holder to reproduce the material. To view a copy of this license, visit http://creativecommons.org/licenses/by/4.0/ 